Dokuz Eylül Üniversitesi-Mühendislik Fakültesi

Fen ve Mühendislik Dergisi

Cilt 20, Sayı 60, Eylül, 2018
Dokuz Eylul University-Faculty of Engineering Journal of Science and Engineering Volume 20, Issue 60, September, 2018

DOI: $10.21205 /$ deufmd. 2018206060

\title{
Linyit Kömürü İşletmelerinde Havalandırma Planlamasına Alternatif Çözümler
}

\author{
Alper GÖNEN ${ }^{* 1}$, Tahir MALLI²
}

${ }^{1}$ Dokuz Eylül Üniversitesi, Mühendislik Fakültesi, Maden Mühendisliği Bölümü, 35390, İzmir 1 (ORCID:0000-0001-7025-4063)

2 (ORCID:0000-0002-5786-9132)

(Alınış / Received: 26.03.2018 Kabul / Accepted: 08.04.2018

Online Yayınlanma / Published Online: 15.09.2018)

Anahtar Kelimeler Yeraltı Madenciliği Havalandırma, Gaz içeriği

Özet: Yeraltı kömür ocaklarında madencilik oparasyonlarının temel bileșenlerinden birini olușturan havalandırmanın amacı, çalışma bölgelerine yeterli miktarda temiz havanın gönderilmesini sağlamaktır. Artan işletme derinlikleri, mekanizasyon derecesi ve buna bağlı üretim kapasitelerinde artış, uzunayak içerisinde kömür tozu , zehirli ve patlayıcı gazlar ve ısının çalışma ortamdan uzaklaştırılması işlemini çok daha fazla önemli hale getirmektedir. Ülkemizde linyit kömür işletmeleri, mevcut maden derinlikleri ve gaz içeriği bakımından az-orta gazlı ocak kategorisindedir. Artan ișletme derinliği ve üretim kapasitesi ile beraber üretilen bir ton kömür başına gaz gelirinin artacağı öngörüldüğünde, mevcut tek girişli dönümlü $U$ havalandırma sisteminin havalandırma açısından handikaplarının olacağı açıktır. $\mathrm{Bu}$ çalışmada alternatif havalandırma şebekeleri ekonomiklik ve emniyet açısından irdelenmiş, avantaj ve dezavantajları ortaya konulmuştur.

\section{Alternative Solutions for Mine Ventilation Planning for Lignite Coal Mines}

\section{Keywords}

Underground

Mining,

Ventilation,

Gas Content,

\begin{abstract}
The main aim of ventilaiton, which is a basic part of all mine operations, is to provide sufficient quantity of fresh air to working areas. With increasing mining depth and production capacity related to machanization degree, it makes the process of removing coal dust, toxic and explosive gases and heat from working environment much more important. In Turkey, lignite coal mines are in the category of mildly-moderately gassy in terms of current mining depths and gas content. As it is expected that gas content per ton of coal produced will increase with increased mining depth and production capacity, it is evident that the current single entry $U$ ventilation system will have handicaps in terms of ventilation. In model study alternative ventilation systems have been examined from the economic and safety point of view, and their advantages and disadvantages have been demonstrated.
\end{abstract}




\section{Giris}

Yeraltı madenlerinde havalandırmanın temel amacı, çalışma yapılan yerlerde hava kalitesinin bozulmasina sebep olan kirleticilerin yönetmeliklerle belirlenen sınır değerlerin altında tutulması, emniyetli bir çalıșma ortamının sağlanmasıdır [1]. Artan derinlikle beraber kömür madenlerinde gaz gelirleri de artmaktadır. Mekanizasyon derecesinin artması da üretim kapasitelerinin, uzunayak madenciliğinde ayak ve pano uzunluklarının artmasını sağlamıştır. Bu durum mekanize uzunayaklarda solunabilir ve patlayabilir kömür tozu, zehirleyici ve patlayıcı gazlar ile ısının ortamdan uzaklaştırılması işlemini oldukça kritik ve dikkat edilmesi gereken bir hale getirmiştir.

Ocaklarda; sağlığa uygun solunabilir hava sağlanması, ortamdaki patlama riskinin ve solunabilir toz konsantrasyonunun limitlerin altında tutulması, üretim yöntemine uygun hava özelliklerinin sağlanması ve bu durumun sürdürülebilmesi için uygun havalandırma sisteminin oluşturulması gereklidir. Havasında \% 19'dan az $\mathrm{O}_{2}$, \% 2'den fazla $\mathrm{CH}_{4}, \% 0,5$ 'ten fazla $\mathrm{CO}_{2}, 50$ ppm $(\% 0,005)$ 'den fazla CO olan ortamlarda, tehlikeyi bertaraf etmek amacıyla önleyici faaliyetler ve kurtarma çalışmaları dışında çalışma yapılmaz.

Gaz ve toz problemlerinin fazla olduğu ocaklarda, bu kirleticiler yeterli miktarda hava gönderilerek ocak dışına taşınabilmekte ve ocak havasının gaz ve toz konsantrasyonu tehlike sinırlarının altında tutulabilmektedir [2].

Türkiye'de geleneksel olarak yeraltı kömür işletmelerinde uygulanan uzunayak havalandırma sisteminde birbiriyle bağlantısı olmayan bağımsız iki hazırlık galerisi sürülmekte, tek galeriden temiz hava panoya ve ayağa girmekte, kirlenen hava nakliye yolundan ana havalandirma galerisine ulaşmaktadır.

$\mathrm{Bu}$ sistemde, gerek acil durumlar için gerekse çalışan ayağa gönderilebilecek maksimum hava miktarı galeri kesiti ve hava hızıyla sınırlandırıldığından gaz içeriği ve/veya üretim kapasitesi yüksek işletmelerde ayak içi havalandırma kontrolünü zorlaștırmaktadır. Ayrıca hazırlık galerilerinin bağlantısız galeri şeklinde oluşturulması acil durumlar için bu bölgede çalışan personelin kaçıs imkânı olmaması, yeterli ve sağlıklı bir şekilde hava akışının sağlanamaması sistemin handikaplarıdır.

$\mathrm{Bu}$ çalışmanın amacı ülkemiz linyit kömür işletmelerinde uygulanan ve çoğu zaman sorunlu uzunayak havalandırma sistemlerinin geliştirilmesi ve düzeltilmesine yönelik yapılacak rasyonel planlama ve tasarımlarla ideal çalışma koşullarının oluşturulmasına odaklanmak ve olası alternatif maden havalandırma şebekeleri karşılaştırmaktır.

\section{Uzunayak Havalandırma Planlaması}

İşletme derinliklerinin artması ile birlikte kömür madenlerinde gaz gelirinin de arttı̆̆ 1 bilinmektedir. Ayrıca artan mekanizasyon derecesi üretim miktarlarının da artmasını sağlamıştır. Günümüz uzunayak madenciliğinde ayak uzunlukları $400 \mathrm{~m}$, pano uzunlukları ise 3000 m'ye kadar yükselmiștir. Ayrıca yeraltı kömür ocaklarında artan derinlikle beraber metan gelirinin artması olasılığı ocak havasının kontrol gereksinimini daha önemli hale getirmektedir.

Tablo 1'de gaz içeriklerinde bağlı olarak ocakların sınıflandırılması verilmiştir. [3]. Gaz içeriği, üretilen bir ton kömür sonucu açığa çıkan gaz miktarını temsil etmektedir. Buna göre $2,8 \mathrm{~m}^{3} /$ ton'dan az gaz geliri olan ocaklar "az gazlı" sınıfa girmekte, $8,5 \mathrm{~m}^{3} /$ ton'dan daha fazla gaz 
içeriğine sahip kömür damarları "çok gazlı" olarak sinıflandırılmaktadır.

Tablo 1. Gaz içeriğine bağlı ocakların sinıflandirılması

\begin{tabular}{lcc}
\hline Kategori & $\begin{array}{c}\text { *Derinlik } \\
\text { (m) }\end{array}$ & $\begin{array}{c}\text { Gaz içeriği } \\
\left(\mathbf{m}^{3} \text { /ton }\right)\end{array}$ \\
\hline Az gazlı & $<180$ & $<2,8$ \\
Orta gazlı & $180-360$ & $2,8-8,5$ \\
Çok gazlı & $360-900$ & $8,5-19,8$ \\
\hline * Bitümlü kömürler için &
\end{tabular}

* Bitümlü kömürler için

Ülkemizde, Kütahya Gediz bölgesindeki bir kömür ocağı için yapılan çalışmada, gaz içeriğinin $3,3 \mathrm{~m}^{3}$ /ton olduğu ve azorta gazlı ocak kategorisinde olduğu değerlendirilmiştir [4]. Soma havzası Eynez bölgesinde kömür damarının gaz içeriğinin belirlenmesine yönelik yapılan desorpsiyon testlerine dayalı çalışmalarda ise gaz içeriği $400 \mathrm{~m}$ derinlik için $0,5 \mathrm{~m}^{3} /$ ton, $600 \mathrm{~m}$ derinlik için $1,5 \mathrm{~m}^{3} /$ ton olarak tespit edilmiştir [5].

Eynez bölgesindeki ocaklarda yapılan testlere göre, Soma havzası kömürlerinin kendiliğinden yanmaya yatkınlıkları yüksek olarak belirlenmiștir [6]. Gaz içeriği değerleri daha yüksek olan Zonguldak Armutçuk Büyükdamar'da doğrudan yavaş ve hızlı çözünme yöntemleri kullanılarak yapılan çalışmalarda, ortalama gaz içeriğinin 10$12 \mathrm{~m}^{3} /$ ton kabul edilebileceği belirtilmektedir [7]. Yukarıdaki bilgiler ışığında ülkemiz linyit kömürlerinin azorta gazlı, taşkömürlerinin ise yüksek gazlı kategoride olduğu anlaşılmaktadır. Havalandırma planlarının yapılmasında ve hava ihtiyacının belirlenmesinde bu faktör belirleyici olmaktadır.

Türkiye'de geleneksel olarak yeraltı kömür işletmelerinde geri dönümlü veya ilerletimli uzunayak yöntemi uygulanmaktadır. Bu yöntemlerde tek girişli dönümlü "U" tipi havalandırma sistemi kullanılmakta olup, temiz hava panoya malzeme galerisinden girmekte, ayağı dolaşarak kirlenen hava nakliye yolundan çıkarak ana havalandırma galerisine bağlanmaktadır. İlerletimli sistemde giriş havasının bir kısmı göçük bölgesinden kaçak yapabilmekte, kendiliğinden yanmaya yatkın kömürlerin üretimi esnasında göçük bölgesinde ocak yangınlarının çıkmasına neden olabilmektedir. Bu durum göçük bölgesinde biriken gazların ocak havasını bozmasına neden olmakta, dönümlü ayaklarda bu sorunlar ortadan kalkmaktadır [1].

Ayrıca tek girişli " $U$ " tipi havalandırmanın bir bașka dezavantajı da hazırlık galerilerinin "kör baca" olarak isimlendirilen bağlantısız galeri şeklinde oluşturulmasıdır. $\mathrm{Bu}$ durumda acil durumlar için bu bölgede çalışan personelin kaçış imkânı olmaması ve sağlıklı bir şekilde havalandırma sirkülasyonu sağlanamaması diğer olumsuzluklarıdır.

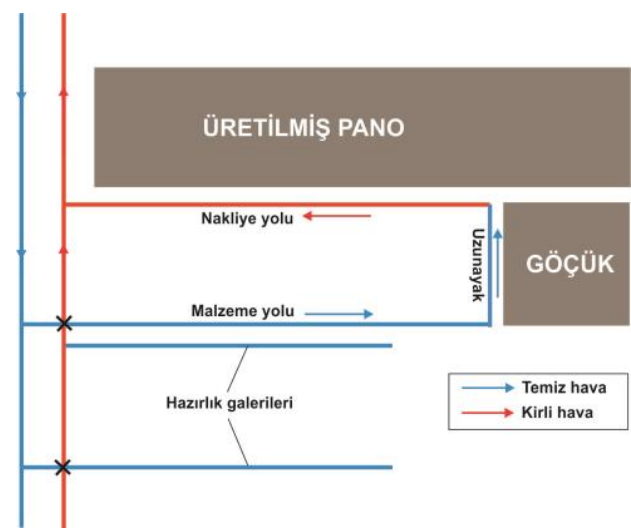

Şekil 1. Tek girişli dönümlü “U” tipi havalandırma

$\mathrm{Bu}$ dezavantajlarına karşın tek temiz hava girişli "U" sistem havalandırma ülkemiz ve Avrupa kömür madenlerinde yaygın olarak kullanılmaktadır (Şekil 1). Avustralya ve ABD gibi yüksek gaz içeriğine sahip kömür damarlarında uzunayakta üretim öncesi metan drenajı yapılarak kömür gaz içeriği 4-6 m³/ton aralığına kadar düşürülmekte ardından üretime başlanmakta ve $\mathrm{CH}_{4}$ 
konsantrasyonunu limit değerler altında tutabilmek için en az iki hatta üç temiz hava girişli havalandırma sistemleri uygulanmaktadır [8]. Böylelikle gaz geliri yüksek ocaklar için ayak içi havalandırmasının sağlanmasında daha güvenli ve kaçış alternatiflerinin olduğu havalandırma planları geliștirilmiştir (Şekil 2). Buna göre, 6 adet ana havalandirma galerisi bulunmakta, bunlardan üç tanesinden temiz hava gönderilirken, diğer üçü dönüş havası olarak kullanılmaktadır. Ocaktaki gaz gelirine bağlı olarak en az iki veya üç hazırlı galerisi sürülerek pano oluşturulmaktadır. Avustralya'da

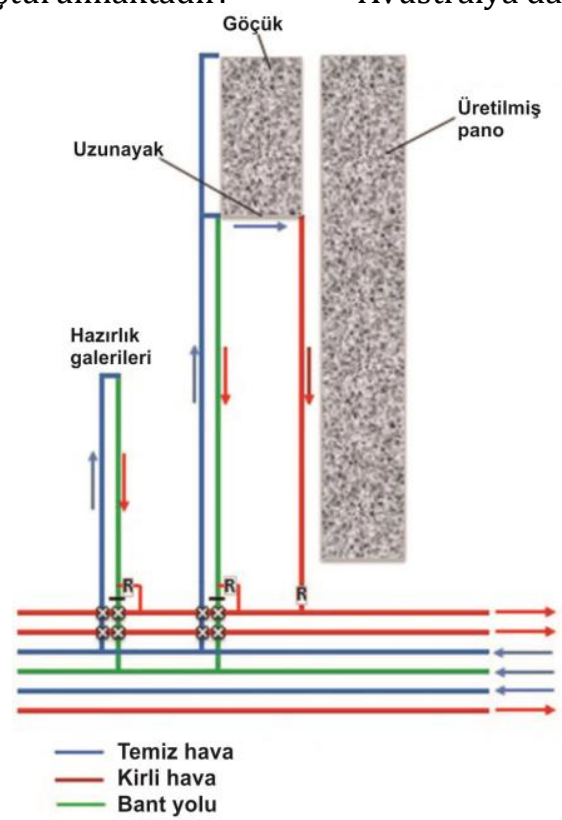

uzunayak yöntemiyle üretim yapılan 13 mekanize kömür işletmesinde yapılan bir araștırmaya göre, ayak uzunluklarının 300-400 m, pano uzunluklarının ise 860 $3500 \mathrm{~m}$ arasında değiștiği (ortalama $2500 \mathrm{~m}$ ) tespit edilmiştir. Ocak için gerekli toplam hava miktarı 54 ile 115 $\mathrm{m}^{3} / \mathrm{sn}$ arasında değișmekte (ortalama 82 $\mathrm{m}^{3} / \mathrm{sn}$ ), ayağa giren hava ise $37-77 \mathrm{~m}^{3} / \mathrm{sn}$ (ortalama $57 \mathrm{~m}^{3} / \mathrm{sn}$ ) olarak ölçülmüştür. Pano uzunluğuna bağlı olarak, pano içi basınç düșmesi 250-1320 Pa arasında değișirken, ortalama $790 \mathrm{~Pa}$ olarak ölçülmüștür [9].

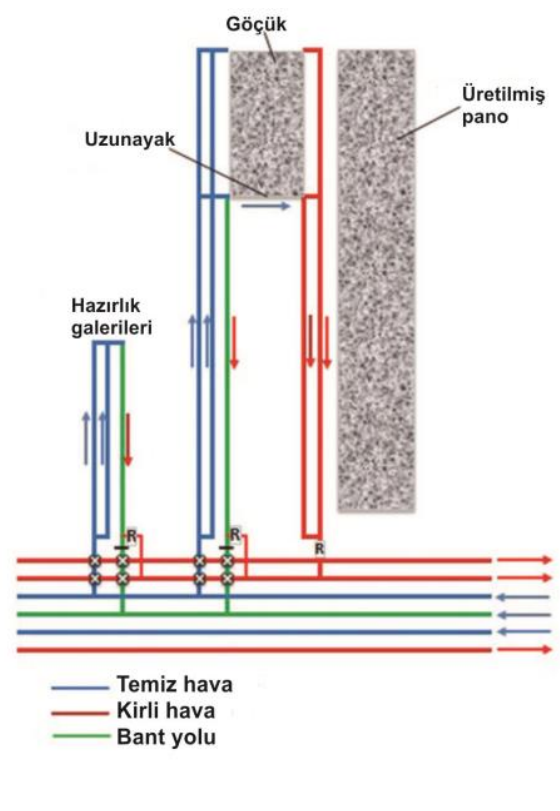

Şekil 2. Avustralya'da uygulanan iki girişli (a) ve üç girişli (b) U tipi havalandırma sistemi

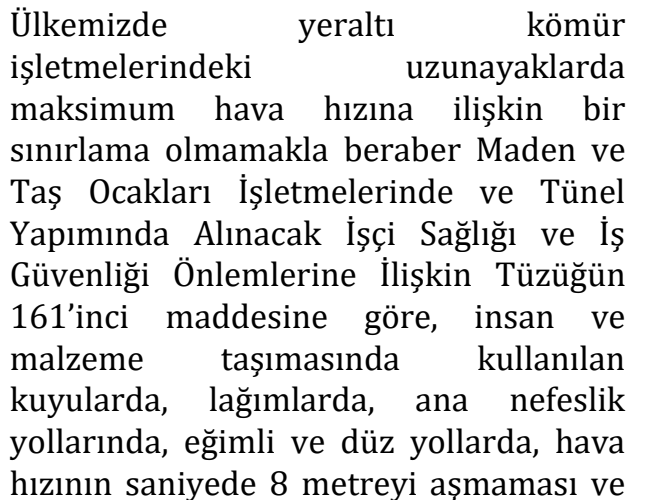

her durumda $0,5 \mathrm{~m} / \mathrm{s}^{\prime}$ den az olmaması istenmektedir. Yüksek hava hızı işçi sağlığı ve ocak iklimini olumsuz etkilemektedir. Genel bir kural olarak çalışma yapılan bölgelerde çökmüş haldeki tozun artan hava hızı ile girdaplanması ve yeniden ocak havasında karışma ihtimaline karşın 1-3 $\mathrm{m} / \mathrm{sn}$ limitlerinde tutulması ve $4 \mathrm{~m} / \mathrm{sn}$ hava hızının aşılmaması önerilmektedir (Şekil 3) [10]. Hava hızının $4 \mathrm{~m} / \mathrm{sn}^{\prime}$ nin üzerine çıkarılmasının zorunlu olduğu 
durumlarda, oldukça etkin bir toz bastırma sisteminin kullanılması gerekmektedir.

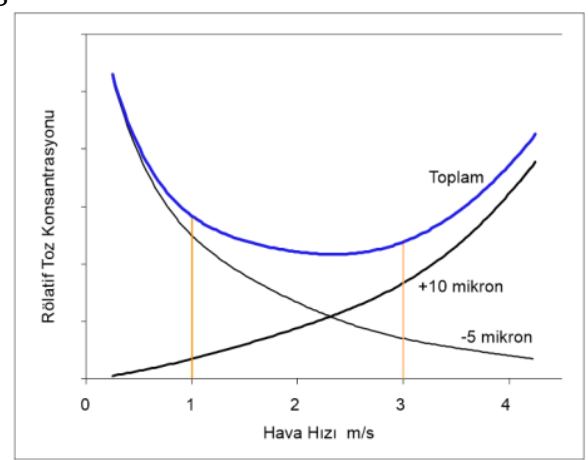

Şekil 3. Hava hızı- toz konsantrasyonu ilişkisi

Ocak havalandırma şebekeleri yeni yolların açılması veya kapanması, yeni üretim bölgelerine geçilmesi ile birlikte dinamik bir şeklide değişmekte, hava debisi ve fan güçlerinin hesaplanması gibi işlemler daha karmaşı hale gelmektedir. Havalandırma şebeke analiz programları, bu așamada gerekli hale gelmektedir. Ventsim ${ }^{\mathrm{TM}}$ paket programı havalandırma şebekelerinin üç boyutlu analizinde kolay ve hızlı çözümler sağlamakta ve günümüzde yaygın olarak kullanılmaktadır. Model çalışmada havalandırma șebekesinin analizinde Ventsim programında yararlanılmıştır.

\section{Model Çalışma}

Ülkemizde linyit üretimi yapılan yeraltı ocakları gaz içeriği bakımından az-orta gazlı ocak kategorisinde olup, gaz içerikleri genellikle $2 \mathrm{~m}^{3}$ /ton'dan daha azdır. Model çalışmada ilk olarak 2 $\mathrm{m}^{3} /$ ton gaz içeriği için bir havalandırma analizi yapılmış ve mevcut uygulanan uzunayak havalandırma sistemine göre hesaplamalar yapılmıştır. Bu amaçla model özellikleri Tablo 2'de verilen bir yeraltı kömür işletmesi için havalandırma şebeke analizi gerçekleştirilmiştir. Üretim kapasitesi 10.000 ton/gün olan 180 metre ayak uzunluğuna ve 4 metre kazı yüksekliğine sahip mekanize bir uzunayak için
Ventsim programında havalandırma modeli oluşturulmuştur.

Tablo 2. Modelde yapılan kabuller

\begin{tabular}{lc}
\hline Üretim kapasitesi & 10.000 ton/gün \\
Ayak uzunluğu & $180 \mathrm{~m}$ \\
Pano uzunluğu & $1.000 \mathrm{~m}$ \\
Kömür kalınlığı & $4 \mathrm{~m}$ \\
Kömür eğimi & Yatay \\
Desandre eğimi & $15^{0}$ \\
İşletme derinliği & $350 \mathrm{~m}$ \\
\hline
\end{tabular}

Modelde hava yollarının sürtünme katsayıları belirlenirken, literatürden elde edilen hava yolu tip ve özelliklerine uygun değerler seçilmiştir [10]. Desandreler 1200 metre uzunluğunda olup 15 derece eğime sahiptir (Tablo 3).

Tablo 3. Hava yollarının özellikleri

\begin{tabular}{|c|c|c|}
\hline Havayolu türü & $\begin{array}{c}\text { Faydalı } \\
\text { kesit } \\
\left(\mathrm{m}^{2}\right)\end{array}$ & $\begin{array}{c}\text { Sürtünme } \\
\text { katsayısı } \\
\left(\mathrm{kg} / \mathrm{m}^{3}\right)\end{array}$ \\
\hline Desandreler & 16,9 & 0,0075 \\
\hline $\begin{array}{l}\text { Ana nakliye ve } \\
\text { havalandırma }\end{array}$ & 16,9 & 0,0075 \\
\hline $\begin{array}{l}\text { Pano tavan - } \\
\text { taban yolları }\end{array}$ & 13,1 & 0,012 \\
\hline Bağlantı yolları & 13,1 & 0,012 \\
\hline Uzunayak & 18 & 0,035 \\
\hline $\begin{array}{l}\text { Havalandırma } \\
\text { ve acil çıkış } \\
\text { kuyusu }\end{array}$ & 3,1 & 0,005 \\
\hline
\end{tabular}

Ocak içerisinde $\mathrm{CH}_{4}$ miktarının \%1'in altında tutulacağı ve giriş havasında \% $0,15 \mathrm{CH}_{4}$ olacağı varsayılarak, $2 \mathrm{~m}^{3} /$ ton gaz içeriğine göre yapılan hesaplamalarda uzunayak için gerekli hava miktarı $30 \mathrm{~m}^{3} / \mathrm{sn}$ olarak tespit edilmiştir. Hazırlık galerilerinin her biri için kazı arınına $0,5 \mathrm{~m} / \mathrm{sn}$ hızında 7 $\mathrm{m}^{3} / \mathrm{sn}$ gerekli havanın gönderilebilmesi için vantilatör çıkışı $9,5 \mathrm{~m}^{3} / \mathrm{sn}$ olan 2 
adet tali vantilatör kullanılması planlanmıştır. Ana nakliye ve ana havalandırma galerisi açlacak olan bağlantı galerilerinden ve pano içi geçiş galerilerinden kaynaklı toplam hava kaçakları ise $16 \mathrm{~m}^{3} / \mathrm{sn}$ 'dir. Böylece ocak için gerekli toplam hava miktarı 65 $\mathrm{m}^{3} / \mathrm{sn}$ olmaktadır (Şekil 4). Ayakta hava hızl 1,7 m/sn'dir. Bu durumda ocak direnci $0,1075 \mathrm{Ns}^{2} / \mathrm{m}^{8}$ olup, $45 \mathrm{~kW}$ gücüne sahip ana vantilatör seçilmesi gerekmektedir. Ana vantilatör havalandırma desandresi çıkışında yeryüzünde ve emici sistem çalışmaktadır.

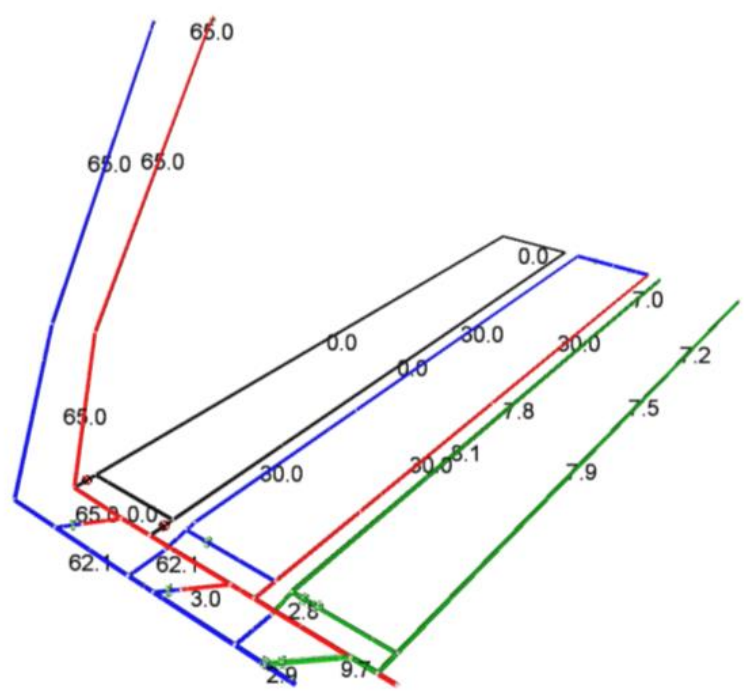

Şekil 4. $2 \mathrm{~m}^{3}$ /ton gaz içeriği için havalandırma planı

Artan derinlik ile beraber gaz içeriğinin de artması beklenir. Kömür damarının gaz içeriğinin iki katına çıkarak $4 \mathrm{~m}^{3} /$ ton olması durumunda, aynı ocak için uzunayakta gerekli hava miktarı da iki katına çıkacak yani $60 \mathrm{~m}^{3} / \mathrm{sn}$ olacaktır. Bu yeni durum için 4 farklı havalandırma şebekesi Ventsim ${ }^{\mathrm{TM}}$ programinda tasarlanmış ve gerekli hesaplamalar yapılmıștır. Tüm durumlarda havalandırma için ayak faydalı kesiti 18 $\mathrm{m}^{2}$ alınmıştır. $\mathrm{Bu}$ durumda hava hızı 3,3 $\mathrm{m} / \mathrm{sn}$ yani kabul edilebilir bir değer olacaktır.

Ülkemizde genel olarak uygulanan tek girişli dönümlü $U$ sistemde ayağa gönderilecek olan havanın debisi ayağa giren havanın hızı ve net ayak kesit alanı ile sinırlandırılmaktadır. Ayrıca 20003000 metreyi bulan pano hazırlık galerilerinin kör ve bağlantısız olarak tek seferde açılması ve acil kaçıș yollarının yetersizliği de sistemin diğer handikaplarındandır (Şekil 5). $\mathrm{Bu}$ durumda ocağa giren $95 \mathrm{~m}^{3} / \mathrm{sn}$ havanın $60 \mathrm{~m}^{3} / \mathrm{sn}$ 'si uzunayağa, $19 \mathrm{~m}^{3} / \mathrm{sn}^{\prime} \mathrm{si}$ iki hazırlık galerisine gönderilecek olup, sistemde hava kaçakları toplam $16 \mathrm{~m}^{3} / \mathrm{sn}$ olacaktır. Model sonuçlarına göre ocak basinci 1308,7 Pa ve ocak direnci 0,142 $\mathrm{Ns}^{2} / \mathrm{m}^{8}$ ve gerekli ana vantilatör gücü 186,9 kW'dır. Bu sonuçlara göre ocak direnci ve hava debisi, yüksek ocak basincl yaratmakta ve sebeple ana fan gücü oldukça artmaktadır.

$\mathrm{Bu}$ sistemin dezavantajlarının giderilmesi ve sistemin iyileştirilmesi amacıyla pano içi çift temiz hava girişli ve birbirlerine geçiş galerileriyle bağlantılı hazırlık galerilerinin açılması planlanmıştır. Böylece işyeri güvenliği ve işçi sağlığı açısından daha uygun çalışma 
ortamlarının sağlanabilmesi amacıyla önerilmiştir. alternatif şebekeler tasarlanarak aşağıda

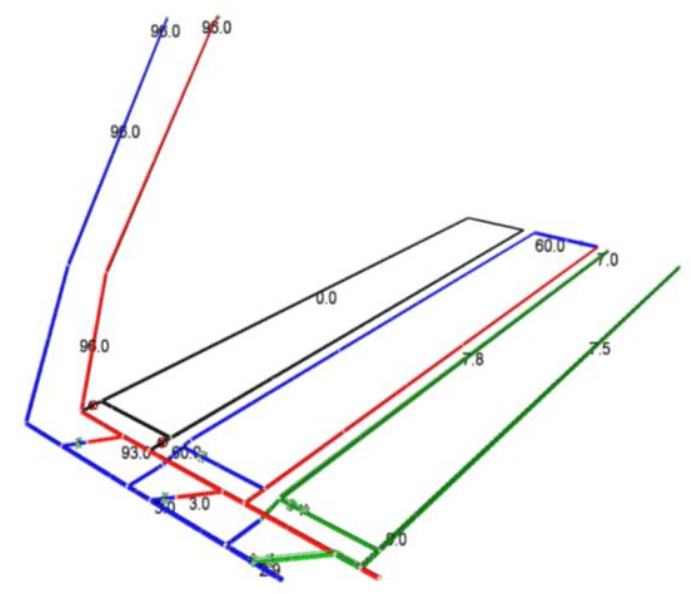

Şekil 5. Mevcut tek girişli dönümlü U sistem havalandırma

Alternatif olarak planlanan çift temiz hava girișli dönümlü $U$ sisteminde birbirine $250 \mathrm{~m}$ aralıklarla bağlantılı oluşturulan hazırlık galerileri toplam galeri uzunluğunu arttırmasına rağmen, ayağa aynı miktarda $\left(60 \mathrm{~m}^{3} / \mathrm{sn}\right)$ hava gereksinimi daha düşük bir ana fan gücüyle sağlanabilmektedir. Bunun sebebi paralel bağlı yollarda toplam basınç düşmesi ile her bir koldaki basınç düşme miktarlarının birbirine eşit olmasıdır. $\mathrm{Bu}$ durumda $60 \mathrm{~m}^{3} / \mathrm{sn}$ uzunayağa, $19 \mathrm{~m}^{3} / \mathrm{sn}$ iki hazırlık galerisine gönderilmekte, sistemde hava kaçakları azalarak toplam $11 \mathrm{~m}^{3} / \mathrm{sn}$ olmakta ve toplam hava miktarı 90 $\mathrm{m}^{3}$ /sn'ye düşmektedir. Model sonuçlarına göre, ocak basıncı mevcut sisteme göre daha düşük bir değere 962,3 $\mathrm{Pa}$ ve ocak direnci 0,1188 $\mathrm{Ns}^{2} / \mathrm{m}^{8}$ ye düşmekte ve $127,8 \mathrm{~kW}$ gücünde ana fan seçilmesi yeterli olmaktadır. Bu sonuçlara göre alternatif olarak mevcut $U$ sistemin birbirine bağlantılı galeriler ile oluşturulması durumunda daha düşük ocak direnci ve hava miktarına gereksinim duyulmaktadır. Bu sayede daha düşük bir ana fan gücüyle ocağın havalandırması sağlanabilmektedir (Şekil 6). 


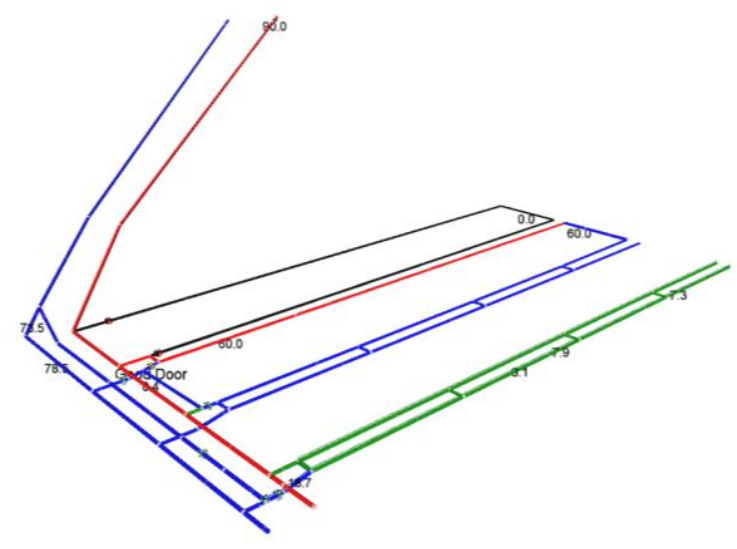

Şekil 6. Çift girişli dönümlü U sistem havalandırma alternatifi

Bir diğer alternatif olan çift girişl dönümlü ve arkadan çıkışlı havalandırma sistemi Şekil 7'de verilmiştir. $\mathrm{Bu}$ sistemin çalıșma prensibi, U sistemde arkadan emici fanın kurulduğu üçüncü bir maden açıklığının açılması ile bir başka hava çıkış yolunun oluşturulmasına dayanmaktadır. $\mathrm{Bu}$ nefeslik aynı zamanda kaçamak yolu olarak da emniyeti arttırmaktadır. Bu sistemde açılması gereken hazırlık galerileri daha fazla olup havalandırma yöntemi sürekli galerilerin açılmasını gerekli kılmaktadır. Acil durumlar için yeterli ve güvenli olup orta ve çok gazlı ocaklar için ideal bir planlamadır. Ancak kendiliğinden yanmaya yatkın kömür işletmeleri için uygun değildir. Uzunayağa aynı miktarda $60 \mathrm{~m}^{3} / \mathrm{sn}$ hava gereksinimi sağlamak için havalandırma desandresi çıkışında 146,6 kW'llk ana emici fan ve havalandırma kuyusunda ise $13 \mathrm{~kW}$ 'llk küçük bir fan gereklidir. Ocağa desandreden giren havanın debisi 105 $\mathrm{m}^{3} / \mathrm{sn}^{\prime}$ dir. Kirlenen havanın $90 \mathrm{~m}^{3} / \mathrm{sn}$ 'si hava dönüş desandresinden, 15 $\mathrm{m}^{3} / \mathrm{sn}^{\prime} \mathrm{si}$ ise pano arkasında açlan havalandirma kuyusundan çekilmektedir. Bu durumda toplam ocak basıncl 1042,9 Pa'dır. Ocak direnci $0,0946 \mathrm{Ns}^{2} / \mathrm{m}^{8}$ gibi oldukça düşük bir değere düşmektedir.

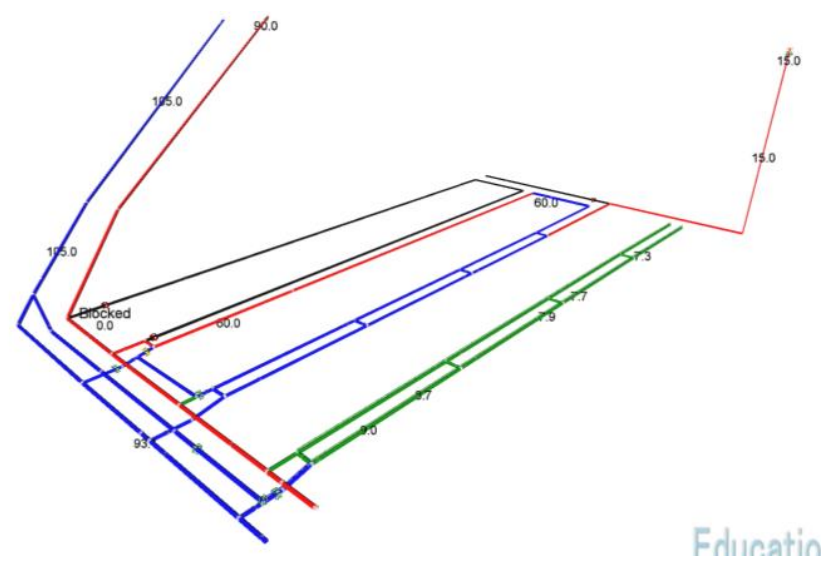

Şekil 7. Çift girişli dönümlü ve arkadan çıkışlı havalandırma alternatifi 
Şekil 8'de çift girişli dönümlü ve arkadan girişli havalandırma sistemi görülmektedir. $\mathrm{Bu}$ sistem gerekli fan gücü ve elektrik tüketimi dikkate alındığında oldukça güvenli ve aynı zamanda ekonomiktir. Ancak açılması gereken hazırlık galerileri fazladır ve sürekli galerilerin açılmasını gerekli kılmaktadır. Acil durumlar için yeterli ve güvenli olmasına rağmen kendiliğinde yanmaya yatkın kömür işletmeleri için uygun değildir.

Uzuanayağa aynı miktarda $60 \mathrm{~m}^{3} / \mathrm{sn}$ hava gereksinimi sağlamak için ana fan gücü $112.5 \mathrm{~kW}$ 'ya düşmektedir. Ocak direnci $0,1038 \mathrm{Ns}^{2} / \mathrm{m}^{8}$ 'dir. Temiz hava $75 \mathrm{~m}^{3} / \mathrm{sn}$ hava giriș desandresinden, 15 $\mathrm{m}^{3} / \mathrm{sn}$ doğal havalandırma ile havalandırma kuyusundan girmektedir. Vantilatörün yaratması gereken toplam basınç farkı 840,8 $\mathrm{Pa}^{\prime}$ a düşmektedir. Sistem Doğal havalandırma basıncı (DHB) ile desteklendiği için oldukça avantajlıdır.

\section{Değerlendirme ve Sonuçlar}

$\mathrm{Bu}$ çalışmada madenlerde ideal çalışma koşullarının oluşturulması ve acil durum kaçış yollarının tasarlanması için olası alternatif maden havalandırma şebekeleri karşılaştırılmıș ve model çalışma sonuçları Tablo 4'de özetlenmiştir.

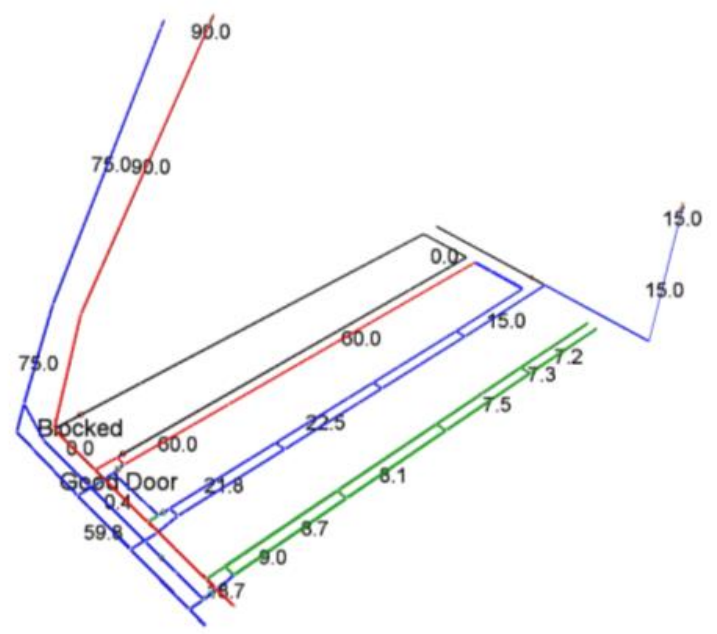

Şekil 8. Çift girişli dönümlü ve arkadan girișli havalandırma alternatifi

Tablo 4. $4 \mathrm{~m}^{3} /$ ton gaz içeriğine göre havalandırma șebeke alternatifleri ve parametreleri

\begin{tabular}{lcccc}
\hline Model çıktıları & $\begin{array}{c}\text { Tek girişli } \\
\text { dönümlü }\end{array}$ & $\begin{array}{c}\text { Çift girişli } \\
\text { dönümlü }\end{array}$ & $\begin{array}{c}\text { Çift girişli } \\
\text { dönümlü ve } \\
\text { arkadan } \\
\text { çlkışlı }\end{array}$ & $\begin{array}{c}\text { Çift girişli } \\
\text { dönümlü ve } \\
\text { arkadan } \\
\text { girișli }\end{array}$ \\
\hline Fan gücü (kW) & 186,9 & 127,8 & $146,6+13$ & $112,5+$ DHB \\
Ayakta hava hızı (m/sn) & 3,3 & 3,3 & 3,3 & 3,3 \\
Ocakta hava miktarı (m³/sn) & 95 & 90 & $90+15$ & $75+15$ \\
Havalandırma şebeke verimi (\%) & 72,2 & 71,7 & 72,2 & 71,3 \\
Toplam galeri uzunluğu (m) & 11.700 & 14.595 & 15.624 & 15.624 \\
Ocak basıncı (Pa) & 1281,5 & 962,3 & 1042,9 & 840,8 \\
Ocak direnci $\left(\mathrm{Ns}^{2} / \mathrm{m}^{8}\right)$ & 0,1420 & 0,1188 & 0,0946 & 0,1038 \\
\hline
\end{tabular}


Model çlktılarına göre;

$\checkmark \quad$ En yüksek ana fan gücü mevcut uygulanan tek girişli dönümlü $U$ havalandırma sisteminde 186,9 kW oluşmaktadır.

$\checkmark \quad$ Düşük ana fan gücü $112,5 \mathrm{~kW}$ ile çift girişli dönümlü ve arkadan girişli sistemde sağlanmaktadır.

$\checkmark \quad$ En düşük ocak basıncının 840,8 Pa ile çift girişli dönümlü ve arkadan girişli sistemde olduğu görülmektedir.

$\checkmark$ En düşük ocak direnci 0,0946 $\mathrm{Ns}^{2} / \mathrm{m}^{8}$ ile çift girişli dönümlü ve arkadan çıkışlı sistemde gerçekleşmektedir.

$\mathrm{Bu}$ sonuçlara göre mevcut uygulanan tek girişli dönümlü $U$ havalandırma sisteminde yüksek ocak direnci ve hava debisi, yüksek ocak basıncı yaratmakta ve önerilen çift girişli dönümlü $U$ havalandırma sistemine göre gerekli ana fan gücü oldukça artmaktadır. Arkada bir havalandırma kuyusu bulunan arkadan çıkışlı ve girişli alternatiflerde ise daha düşük ocak direnci ve basınçları oluşmakta, daha düşük fan güçleriyle ideal koşulların oluşturulabileceği öngörülmektedir. Ancak bu durumda göçük bölgesinden dolanan hava yangina sebep olabileceğinden kendiliğinden yanmaya yatkın kömür işletmeleri için uygun değildir.

\section{5. Öneriler}

Emniyet ve ekonomik açıdan ideal bir havalandırma sistemi olarak arkadan girişli ve çıkışlı sistemler mevcut uygulanan $\mathrm{U}$ sistemin zaaflarını ve olumsuzluklarını gidermekte ve arkadan ayağa giren ilave hava, ayak havasının gaz konsantrasyonunu düşürmekte acil durumlar için emniyetli bir kaçış yolu oluşturulmaktadır. Ancak üçüncü bir çıkış açılığı̆ın olușturulmasının mümkün olmadığı ve kömürün kendiliğinden yanmaya yatkın olduğu durumlar için alternatif $U$ sistem linyit kömür işletmeleri için uygulanabilir çözüm alternatifleri olarak öngörülmektedir. Ayrıca pano içi nakliye yönü ile giriş havasının yönünün aynı veya ters olması durumunda ocak ve ayak havalandırmasına etkileri de göz önünde bulundurularak diğer faktörlerle birlikte daha ayrıntılı ve kapsamlı çalışmaların yapılması düşünülmektedir. Maden İşyerlerinde İș Sağllğı ve Güvenliği Yönetmeliğinde eklenen bir madde ile kömür damarlarının gaz içeriğinin ve desorpsiyon kapasitelerinin belirlenmesi zorunlu hale getirilmiştir. Böylece ülkemiz kömür damarlarının gaz içeriği açısından bir envanteri oluşturularak kömür sahalarının sınıflandırılması amaçlanmaktadır. Bu çalışma, orta ve yüksek gaz içeriğine sahip kömür damarlarının üretiminin iş güvenliği ve işçi sağlığına uygun olarak tasarlanmasında havalandırma mühendislerine yol gösterici olacaktır.

\section{Kaynakça}

[1] Yalçın, E. 2012. Yeraltı Havalandırması. Dokuz Eylül Üniversitesi, Mühendislik Fakültesi Yayınları No: 336, İzmir.

[2] Yalçın, E. 1999. Havalandırma Şebeke Analiz Programı Yardımı İle Madenlerde Kontrollu Hava Dağılımı, Dokuz Eylül Üniversitesi Fen ve Mühendislik Dergisi, Cilt 1, Sayı 2, 71-79.

[3] Kissell, F. N. 2006. Handbook for Methane Control in Mining. National Institute for Occupational Safety and Health (NIOSH), Publication No. 2006-127.

[4] Şensöğüt, C., Barış, K. 2015. Kömür Damarlarının Gaz İçeriğinin Belirlenmesi; Örnek Bir Uygulama. Çukurova Üniversitesi Mühendislik Mimarlık Fakültesi Dergisi, Adana, 30(1), 223-229.

[5] Fişne, A., Özer, S.C., Esen, O., Üğdül, İ.G. 2015. İmbat Madencilik A.Ș. Soma-Eynez Yeraltı Kömür 
İşletmesi Kömür Damarlarının Gaz İçeriği ve Gaz Bileşiminin Araştırılması, İTÜ Teknokent Ar-Ge Projesi.

[6] Karpuz, C., Güyagüler, T., Bağcl, S., Bozdağ, T., Başarır, H., Keskin, S. 2000. Linyitlerin Kendiliğinden Yanmaya Yatkınlık Derecelerinin Tespiti: Bölüm 2-TKI Yeraltı Ocakları Sonuçları, Sayı: 39/3-4, 14-26.

[7] Didari, V., Oskan, M., Barıș, K. 2015. TTK Armutçuk Müessesesi Büyük Damar Gaz İçeriğinin Doğrudan Ölçme Yöntemiyle Belirlenmesi, Madencilik, Cilt 54, Sayı 2, 3-12.

[8] Halim, A. 2013. Ventilation circuit for large and gassy longwall panels - an Australian perspective, Mining Technology Transactions of the Institutions of Mining and Metallurgy: Section A, Volume 122, Issue 4, 235-242.

[9] Gillies, S., Wu, H. W. 2013. Australian longwall panel ventilation practices, Proceedings of the Coal Operators Conference, University of Wollongong, Australia 176-183.

[10] McPherson, M. J. 1993. Subsurface Ventilation Engineering, Chapman \& Hall, London, United Kingdom. 